\title{
Consanguinity and Genomics
}

Identifying the specific topics that most clearly merited inclusion in this special issue, 22 contributions were invited from geneticists and clinicians working in 41 research centres across 21 countries. The papers, which include original research investigations, case studies and reviews, offer a wide spectrum of detailed perspectives on the influence of consanguinity and community endogamy on the lives of individuals, their families and societies.

The invited authors are all acknowledged experts in their respective fields and our intention is that collectively their contributions will encourage and enable new and exciting insights into the different important aspects of consanguinity. Therefore, the covered topics range from demographic and social aspects of consanguineous marriage [Zlotogora and Shalev, Hosseini-Chavoshi et al., Shaw], consanguinity and population genetics [Pemberton and Rosenberg, Gazal et al., Pippucci et al., Goetz et al.], over the influence of consanguinity on inherited disease profiles at both community [Costa-Motta et al., Gosadi et al., Corry] and national levels [ten Kate et al., Romdhane et al., Girotto et al., Al-Thihli et al.], and the impact of consanguinity across clinical genetics [Abbas and Yunis, Al-Gazali and Hamamy, Bashamboo and McElreavey, Gillespie et al., Al-Herz et al., Di Pierro et al., Iqbal and van Bokhoven], to medico-legal and ethical issues arising from whole exome and whole genome sequencing [Sund and Rehder].

The success of a thematically diverse collection of papers of this nature is necessarily dependent on the commitment of the contributors. It is a pleasure to acknowledge with gratitude the unfailing cooperation of the authors, the indispensable support provided by Katherine Montague as Editorial Administrator, the ongoing encouragement of Dr. Françoise Clerget-Darpoux, the Editor of Human Heredity, and the sustained commitment by the publishers S. Karger AG.

Giovanni Romeo, Bologna Alan H. Bittles, Perth 